\title{
Characterization of the Quality Factor Due to the Static Prestress in Classical Caputo and Caputo-Fabrizio Fractional Thermoelastic Silicon Microbeam
}

\author{
Hamdy M. Youssef ${ }^{1,2, *(D)}$, Alaa A. El-Bary ${ }^{3,4}$ and Eman A. N. Al-Lehaibi ${ }^{5}$ (D) \\ 1 Mechanical Engineering Department, College of Engineering and Islamic Architecture, \\ Umm Al-Qura University, Makkah 21955, Saudi Arabia \\ 2 Mathematics Department, Faculty of Education, Alexandria University, 21500 Alexandria, Egypt \\ 3 Arab Academy for Science, Technology and Maritime Transport, P.O. Box 1029 Alexandria, Egypt; \\ aaelbary@aast.edu \\ 4 National Committee for Mathematics, Academy of Scientific Research and Technology, 11516 Cairo, Egypt \\ 5 Mathematics Department, Al-Lith University College, Umm Al-Qura University, Al-Lith 28433, Saudi Arabia; \\ dremanallehaibi@gmail.com \\ * Correspondence: youssefanne2005@gmail.com
}

Citation: Youssef, H.M.; El-Bary, A.A.; Al-Lehaibi, E.A.N. Characterization of the Quality Factor Due to the Static Prestress in Classical Caputo and Caputo-Fabrizio Fractional Thermoelastic Silicon Microbeam. Polymers 2021 , 13, 27. https://dx.doi.org/10.3390/ polym13010027

Received: 10 December 2020 Accepted: 21 December 2020 Published: 23 December 2020

Publisher's Note: MDPI stays neutral with regard to jurisdictional claims in published maps and institutional affiliations.

Copyright: () 2020 by the authors. Licensee MDPI, Basel, Switzerland. This article is an open access article distributed under the terms and conditions of the Creative Commons Attribution (CC BY) license (https: / / creativecommons.org/ licenses/by/4.0/).

\begin{abstract}
The thermal quality factor is the most significant parameter of the micro/nanobeam resonator. Less energy is released by vibration and low damping, which results in greater efficiency. Thus, for a simply supported microbeam resonator made of silicon ( $\mathrm{Si}$ ), a thermal analysis of the thermal quality factor was introduced. A force due to static prestress was considered. The governing equations were constructed in a unified system. This system generates six different models of heat conduction; the traditional Lord-Shulman, Lord-Shulman based on classical Caputo fractional derivative, Lord-Shulman based on the Caputo-Fabrizio fractional derivative, traditional Tzou, Tzou based on the classical Caputo fractional derivative, and Tzou based on the Caputo-Fabrizio fractional derivative. The results show that the force due to static prestress, the fractional order parameter, the isothermal value of natural frequency, and the beam's length significantly affect the thermal quality factor. The two types of fractional derivatives applied have different and significant effects on the thermal quality factor.
\end{abstract}

Keywords: static prestress; microresonator; Lord-Shulman; dual-phase lag; quality factor; fractional derivative; Caputo-Fabrizio

\section{Introduction}

Several applications are essential for micro-and nanoelectric resonator applications, such as mechanical signal processing, scanning, microscopes, and ultrasensitive mass detection. The energy dissipation mechanism for improving micro/nanoelectric resonators is being investigated [1-4]. Zener has introduced and given an approximately analytical form of the heat quality factor in thermoelastic dissipation. In the handling of viscothermoelastic, Zener also explored thermoelastic damping in beams [5-7]. Many scholars have performed various studies on the classic Fourier heat conduction rule for thermoelastic damp. Lifshitz and Roukes [8] gave an exact expression for thermoelastic damping. Sun et al. [9] studied the thermoelastic damping of a beam resonator based on a non-Fourier heat conduction equation. Sharma and Sharma [10] introduced the thermal damping in a circular plate of microresonators in the context of the Lord-Shulman theory of generalized thermoelasticity theory (L-S).

Tzou introduced the dual-phase-lag heat conduction (DPL) in which the temperature gradient and heat flux lag times have been included [11,12]. Many scientists and authors have applied this model to heat transfer problems [13], physical systems [14-18], and thermoelastic damping vibration $[19,20]$. Guo et al. [21,22] studied the thermoelastic 
damping theory of micro- and nanomechanical resonators using the DPL model. The DPL is used in mathematics, physics and many other scientific fields, such as applied mechanics, chemicals, biology, etc., of a fractional derivative definition [23-26]. The fractional derivative is a powerful way to clarify the history and patrimony of different materials and processes. The definition of fractional derivatives was found to be more applicable to real-world modeling applications than the regular integer derived [27-29]. Several scholars have concentrated more on establishing or producing a new concept of fractional derivative, such as the Riemann-Liouville and the Caputo, [30-32]. Youssef developed a theory of thermoelasticity based on fractional heat conductivity and other thermoelasticity theories [33,34]. Sherif et al. introduced a different theory of thermoelasticity using the methodology of fractional calculus [35]. The fractional calculus models are more consistent than standard ones since they predict delayed effects. Some researchers realized that new fractional derivatives could satisfy the need with some special or nonsingular kernels by providing an exponential solution to the single kernel issue found in the Liouville-Caputo, Riemann-Liouville, Caputo and Fabrizio fractional derivatives concepts [36,37].

Small size leads to an increase in the natural frequency of the thermoelastic resonator. The resonators' normal frequency can also be influenced by an axial force like static stress $[3,38]$. The natural frequency decreases the pressure power, while the lower frequency increases the energy of the tensile. For experimental tests, the frequency change of the tuning resonators was used $[3,39]$.

Therefore, in the present study, we will construct an analytical solution of a thermal model of a silicon microbeam resonator subjected to static prestress based on two different types of fractional derivative definitions. We will calculate the thermal quality factor in the context of the new Caputo-Fabrizio fractional derivative which will supply us with new and different results. The governing equations will be constructed in the context of Lord-Shulman and dual-phase-lag heat conduction models. The thermal quality factor will be introduced and calculated for different cases and various values of parameters. This paper introduces not only different and new comparisons between the Lord-Shulman (L-S) and dual-phase-lag (DPL) models but also between two types of fractional derivative and the traditional derivative which has not been published before this work.

\section{Model Formulation}

Tzou proposed a dual-phase lag with two distinct relaxation time parameters in the conventional thermal flow model and adherence to the effect of micro/nanostructure interactions [40-43]:

$$
-K \nabla T\left(x, t+\tau_{T}\right)=q\left(x, t+\tau_{q}\right)
$$

where $T$ is the temperature, $K$ is the heat conductivity, $q$ is the heat flux, and $t$ is the time, $\tau_{q}, \tau_{T}$ are the phase lag of the heat flux and the phase lag of the temperature gradient, respectively.

Expand the two sides of the Equation (1) considering the fractional-order definition to obtain:

$$
-K\left[\nabla T(x, t)+\tau_{T}^{\beta} D_{t}^{\beta} \nabla T(x, t)\right]=q(x, t)+\tau_{q}^{\beta} D_{t}^{\beta} q(x, t)
$$

The classical Caputo and Caputo-Fabrizio define the fractional derivative operator $D_{t}^{\beta}=\frac{d^{\beta}}{d t^{\beta}}$ in the equation as follows $[34,36,44-47]$ :

$$
D_{t}^{\beta} f(t)=\left\{\begin{array}{lll}
\frac{1}{\Gamma(1-\beta)} \int_{0}^{t} f^{\prime}(\xi)(t-\xi)^{-\beta} d \xi & 0 \leq \beta<1 & \text { Classical Caputo } \\
\frac{1}{1-\beta} \int_{0}^{t} f^{\prime}(\xi) \exp \left(-\frac{\beta}{1-\beta}(t-\xi)\right) d \xi & 0 \leq \beta<1 & \text { Caputo - Fabrizio } \\
f^{\prime}(t) & \beta=1 & \text { Normal derivative }
\end{array}\right\}
$$

The constitutive equations of Euler-Bernoulli's microbeam with length $L$, width $b$ and depth $h$ along the $x, y$, and $z$-axes, respectively, have been considered in Figure 1 . The 
moment of inertia is $I$, and applied axial force is $F$, and thermoelastic displacement (lateral deflection) is $w(x, t)$ as [9-12]:

$$
\sigma_{x x}(x, y, z, t)=\sigma_{0}-E y \frac{\partial^{2} w(x, t)}{\partial x^{2}}-E \alpha_{T} \theta(x, y, z, t)
$$

where $\sigma_{0}=\frac{F}{b h}$ is the stress due to the applied axial force, $E$ is the Young's Modulus, and $\alpha_{T}$ is defined as the coefficient of thermal expansion. The reference temperature of the beam is $T_{0}$, and the temperature increment is $\theta=\left(T-T_{0}\right)$.
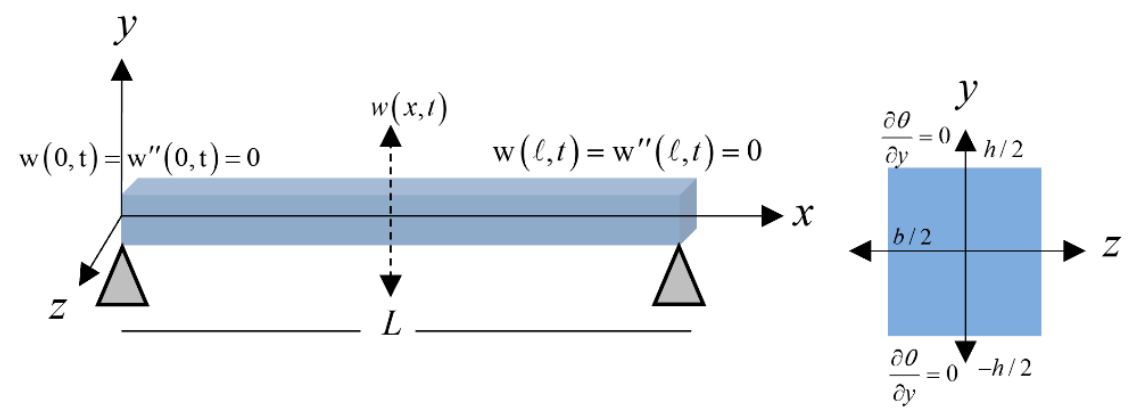

Figure 1. Nanobeam of silicon.

The equation of motion along the beam's length is [12,48-50]:

$$
\frac{\partial^{4} w(x, t)}{\partial x^{4}}-\frac{F}{E I} \frac{\partial^{2} w(x, t)}{\partial x^{2}}+\frac{\alpha_{T}}{I} \frac{\partial^{2} I_{T}(x, y, z, t)}{\partial x^{2}}+\frac{\rho A}{E I} \frac{\partial^{2} w(x, t)}{\partial t^{2}}=0
$$

where

$$
I(x, y, z, t)=\int_{-b / 2}^{b / 2} \int_{-h / 2}^{h / 2} y^{2} d y d z=\frac{b h^{3}}{12}
$$

and

$$
I_{T}(x, y, z, t)=\int_{-b / 2}^{b / 2} \int_{-h / 2}^{h / 2} y \theta(x, y, z, t) d y d z
$$

Equation (5) takes the form

$$
\frac{\partial^{4} w(x, t)}{\partial x^{4}}-\frac{12 F}{E b h^{3}} \frac{\partial^{2} w(x, t)}{\partial x^{2}}+\frac{12 \alpha_{T}}{h^{3}} \frac{\partial^{2}}{\partial x^{2}} \int_{-h / 2}^{h / 2} y \theta(x, y, z, t) d y+\frac{12 \rho}{E h^{2}} \frac{\partial^{2} w(x, t)}{\partial t^{2}}=0
$$

The fractional dual-phase-lag heat equations take the form $[19,20,51]$ :

$$
\left(1+\tau_{T}^{\beta} D_{t}^{\beta}\right) \nabla^{2} \theta(x, y, z, t)=\frac{\partial}{\partial t}\left(1+\tau_{q}^{\beta} D_{t}^{\beta}\right)\left(\frac{\rho C_{v}}{K} \theta(x, y, z, t)+\frac{E \alpha_{T} T_{0}}{K(1-2 v)} \varepsilon(x, y, z, t)\right)
$$

where $v$ is the Poisson's ratio and $C_{v}$ is the specific heat at constant strain.

The volumetric deformations are as follows:

$$
\varepsilon=\varepsilon_{x x}+\varepsilon_{y y}+\varepsilon_{z z}
$$

where

$$
E \varepsilon_{x x}(x, y, z, t)=\sigma_{0}-y E \frac{\partial^{2} w(x, t)}{\partial x^{2}}
$$

and

$$
E \varepsilon_{y y}(x, y, z, t)=E \varepsilon_{z z}(x, y, z, t)=-v \sigma_{0}+v y E \frac{\partial^{2} w(x, t)}{\partial x^{2}}+(1+v) \alpha_{T} E \theta(x, y, z, t)
$$


By making sum the strain components in (12), we obtain

$$
E \varepsilon(x, y, z, t)=(1-2 v) \sigma_{0}-(1-2 v) y E \frac{\partial^{2} w(x, t)}{\partial x^{2}}+2(1+v) \alpha_{T} E \theta(x, y, z, t)
$$

Substituting Equation (13) into the Equation (9), we obtain

$$
\begin{gathered}
\left(1+\tau_{T}^{\beta} D_{t}^{\beta}\right) \nabla^{2} \theta(x, y, z, t)=\eta \frac{\partial}{\partial t}\left(1+\tau_{q}^{\beta} D_{t}^{\beta}\right) \theta(x, y, z, t)+ \\
\frac{\alpha_{T} T_{0}}{K} \frac{\partial}{\partial t}\left(1+\tau_{q}^{\beta} D_{t}^{\beta}\right)\left[2 \frac{(1+v) \alpha_{T}}{(1-2 v)} E \theta(x, y, z, t)-y E \frac{\partial^{2} w(x, t)}{\partial x^{2}}\right]
\end{gathered}
$$

which gives:

$$
\begin{gathered}
\left(1+\tau_{T} D_{t}^{\beta}\right) \nabla^{2} \theta(x, y, z, t)+\frac{\alpha_{T} T_{0} E}{K} y \frac{\partial}{\partial t}\left(1+\tau_{q} D_{t}^{\beta}\right) \frac{\partial^{2} w(x, t)}{\partial x^{2}}= \\
\frac{\partial}{\partial t}\left(1+\tau_{q} D_{t}^{\beta}\right)\left(\eta+\frac{2 E T_{0} \alpha_{T}^{2}(1+v)}{K(1-2 v)}\right) \theta(x, y, z, t)
\end{gathered}
$$

where $\eta=\frac{\rho C_{v}}{K}$.

Hence, the Equation (15) takes the form:

$$
\begin{gathered}
\left(1+\tau_{T}^{\beta} D_{t}^{\beta}\right) \nabla^{2} \theta(x, y, z, t)+\frac{\Delta_{E}}{\alpha_{T}} \frac{\partial}{\partial t}\left(1+\tau_{q}^{\beta} D_{t}^{\beta}\right) y \frac{\partial^{2} w(x, t)}{\partial x^{2}}= \\
\frac{\partial}{\partial t}\left(1+\tau_{q}^{\beta} D_{t}^{\beta}\right)\left(\eta+2 \Delta_{E} \frac{(1+v)}{(1-2 v)}\right) \theta(x, y, z, t)
\end{gathered}
$$

where $\Delta_{E}=\frac{T_{0} \alpha_{T}^{2} E_{0}}{K}$.

Because no gradient exists in the z-direction, then, $\nabla^{2} \theta(x, y, z, t) \approx \frac{\partial^{2} \theta(x, y, t)}{\partial y^{2}}$, therefore, we obtain

$$
\begin{gathered}
\frac{\partial^{4} w(x, t)}{\partial x^{4}}-\frac{12 F}{E b h^{3}} \frac{\partial^{2} w(x, t)}{\partial x^{2}}+\frac{12 \alpha_{T}}{h^{3}} \frac{\partial^{2}}{\partial x^{2}} \int_{-h / 2}^{h / 2} y \theta(x, y, t) d y+\frac{12 \rho}{E h^{2}} \frac{\partial^{2} w(x, t)}{\partial t^{2}}=0 \\
\left(1+\tau_{T}^{\beta} D_{t}^{\beta}\right) \frac{\partial^{2} \theta(x, y, t)}{\partial y^{2}}+\frac{\Delta_{E}}{\alpha_{T}} y \frac{\partial}{\partial t}\left(1+\tau_{q}^{\beta} D_{t}^{\beta}\right) \frac{\partial^{2} w(x, t)}{\partial x^{2}}= \\
\frac{\partial}{\partial t}\left(1+\tau_{q}^{\beta} D_{t}^{\beta}\right)\left(\eta+2 \Delta_{E} \frac{(1+v)}{(1-2 v)}\right) \theta(x, y, t)
\end{gathered}
$$

We consider the following functions:

$$
w(x, t)=W(x) e^{i \omega t}, \theta(x, y, t)=\vartheta(x, y) e^{i \omega t}
$$

where $\omega$ is called the isothermal frequency parameter, and $i=\sqrt{-1}$.

Hence, Equations (17) and (18) will take the forms

$$
\frac{d^{4} W(x)}{d x^{4}}-\frac{12 F}{E b h^{3}} \frac{d^{2} W(x)}{d x^{2}}+\frac{12 \alpha_{T}}{h^{3}} \frac{d^{2}}{d x^{2}} \int_{-h / 2}^{h / 2} y \vartheta(x, y) d y-\frac{12 \rho \omega^{2}}{E h^{2}} W(x)=0
$$

and

$$
\begin{aligned}
& \frac{\partial^{2} \vartheta(x, y)}{\partial y^{2}}+\frac{\Delta_{E} i \omega\left(1+\tau_{q}^{\beta} \delta(\omega, \beta)\right)}{\alpha_{T}\left(1+\tau_{T}^{\beta} \delta(\omega, \beta)\right)} y \frac{d^{2} W(x)}{d x^{2}}= \\
& \frac{i \omega\left(1+\tau_{q}^{\beta} \delta(\omega, \beta)\right)}{\left(1+\tau_{T}^{\beta} \delta(\omega, \beta)\right)}\left(\eta+2 \Delta_{E} \frac{(1+v)}{(1-2 v)}\right) \vartheta(x, y)
\end{aligned}
$$

Through simplifying Equation (21), we applied the following relations [26,35,52,53]:

$$
D_{t}^{\beta}\left(e^{i \omega t}\right)=\delta(\omega, \beta) e^{i \omega t}
$$


where

$$
\delta(\omega, \beta)=\left\{\begin{array}{lr}
\delta_{1}=(i \omega)^{\beta} & \text { Classical - Caputo (C - C) } \\
\delta_{2}=\frac{i \omega}{\beta-i \omega(\beta-1)} & \text { Fabrizio - Caputo (F-C) } \\
\delta_{3}=i \omega & \text { Traditional Derivative }
\end{array}\right\}
$$

\section{Descriptions of the Six Models}

To describe the six different models, we follow the following substitutions:

1. $\beta=1.0, \tau_{T}=0.0, \tau_{q}=\tau_{0}$, and $\delta=\delta_{3}$ represents the traditional Lord-Shulman model with one relaxation time [54].

2. $\quad 0.0 \leq \beta<1.0, \tau_{T}=0.0, \tau_{q}=\tau_{0}$, and $\delta=\delta_{1}$ represents the Lord-Shulman model based on the classical Caputo fractional definition (Lord-Shulman (C-C)).

3. $0.0 \leq \beta<1.0, \tau_{T}=0.0, \tau_{q}=\tau_{0}$, and $\delta=\delta_{2}$ represents the Lord-Shulman model based on the Caputo-Fabrizio fractional definition (Lord-Shulman (F-C)).

4. $\beta=1.0, \tau_{T} \neq \tau_{q} \neq 0.0$, and $\delta=\delta_{3}$ represents the traditional Tzou dual-phase-lag (DPL) model.

5. $\quad 0.0 \leq \beta<1.0, \tau_{T} \neq \tau_{q} \neq 0.0$, and $\delta=\delta_{1}$ represents the Tzou dual-phase-lag (DPL) model based on the classical Caputo fractional definition (Tzou (C-C)) [42].

6. $0.0 \leq \beta<1.0, \tau_{T} \neq \tau_{q} \neq 0.0$, and $\delta=\delta_{2}$ represents the Tzou dual-phase-lag (DPL) model based on the Caputo-Fabrizio fractional definition (Tzou (F-C)).

Equation (21) could be written in the form

$$
\frac{\partial^{2} \vartheta(x, y)}{\partial y^{2}}-\lambda^{2} \vartheta(x, y)=-\alpha y \frac{d^{2} W(x)}{d x^{2}}
$$

where $\lambda^{2}=\frac{i \omega\left(1+\tau_{q}^{\beta} \delta(\omega, \beta)\right)}{\left(1+\tau_{T}^{\beta} \delta(\omega, \beta)\right)}\left(\eta+2 \Delta_{E} \frac{(1+v)}{(1-2 v)}\right)$ and $\alpha=\frac{\Delta_{E} i \omega\left(1+\tau_{q}^{\beta} \delta(\omega, \beta)\right)}{\alpha_{T}\left(1+\tau_{T}^{\beta} \delta(\omega, \beta)\right)}$.

The general solution of the differential Equation (23) takes the form:

$$
\vartheta(x, y)=A \cos (\lambda y)+B \sin (\lambda y)+\frac{\alpha}{\lambda^{2}} y \frac{d^{2} W(x)}{d x^{2}}
$$

The boundary conditions are as follows:

$$
\left.\frac{\partial \vartheta(x, y)}{\partial y}\right|_{y= \pm h / 2}=0
$$

Hence, we obtain

$$
\vartheta(x, y)=\left[y-\frac{\sin (\lambda y)}{\lambda \cos (\lambda h / 2)}\right] \frac{\alpha}{\lambda^{2}} \frac{d^{2} W(x)}{d x^{2}}
$$

From Equations (5), (7), and (19), we obtain

$$
\frac{h}{12 \rho} E f(\omega) \frac{d^{4} W(x)}{d x^{4}}-\frac{E}{\rho b h^{2}} F \frac{d^{2} W(x)}{d x^{2}}=\omega^{2} W(x)
$$

where

$$
f(\omega)=1+\frac{\alpha_{T} b \alpha}{\lambda^{2} I}\left(\frac{h^{3}}{12}+\frac{h}{\lambda^{2}}-\frac{2}{\lambda^{3}} \tan (\lambda h / 2)\right)
$$

Hence, we have

$$
\frac{I E_{\omega}}{\rho A}\left(\frac{d^{4} W(x)}{d x^{4}}-\frac{F}{I E_{\omega}} \frac{d^{2} W(x)}{d x^{2}}\right)=\omega^{2} W(x)
$$

and

$$
E_{\omega}=E f(\omega)
$$


For a simply supported beam, the exact analytical solution for the natural frequency is given as $[9,10,38]$ :

$$
\omega=\frac{\pi}{L \sqrt{\rho A}} \sqrt{\frac{\pi^{2} I E}{L^{2}} f\left(\omega_{0}\right)+F}
$$

where $\omega_{0}$ is the isothermal value of frequency given by [38]:

$$
\omega_{0}=q_{n}^{2} h \sqrt{\frac{E}{12 \rho}}, q_{n} \approx \frac{1}{L}\{4.73,7.853,10.996, \ldots\}, n=1,2,3, \ldots
$$

Hence, we get

$$
\begin{gathered}
\omega=\frac{\pi^{2}}{L^{2}} \sqrt{\frac{I E}{\rho A}} \sqrt{\left(1+\frac{\Delta E b h^{3}}{12 I \varepsilon_{1}}\left(1+\frac{12 \varepsilon 2}{h^{2} \varepsilon 1}-\frac{24}{h^{3}} \tan (\lambda h / 2)\left(\frac{\varepsilon_{1}}{1+\tau_{T} \delta(\omega, \beta)}\right)^{-3 / 2}\right)\right)+\frac{L^{2}}{\pi^{2} I E} F} \\
\text { where } \varepsilon_{1}=\eta+\frac{2 \Delta E(1+v)}{1-2 v}, \varepsilon_{2}=\frac{1+\tau_{T}^{\beta} \delta(\omega, \beta)}{i \omega_{0}\left(1+\tau_{q}^{\beta} \delta(\omega, \beta)\right)} .
\end{gathered}
$$

The thermal quality factor $\left(\frac{1}{Q}\right)$ is defined as the quality of the thermal damping and defined as $[4-7,55,56]$ :

$$
\frac{1}{Q}=2\left|\frac{\operatorname{Im}(\omega)}{\operatorname{Re}(\omega)}\right|
$$

\section{Numerical Results and Discussions}

The relation between the variation of the thermoelastic damping and the beam height $h$, and the beam length $L$ in different values of the applied axial force $F$ on the microbeam will be studied. Simple clamping at the two ends of the microbeam resonator made of silicon will be explored. Hence, the material properties of silicon ( $\mathrm{Si}$ ) will be taken as follows [9]:

$$
\begin{aligned}
& T_{0}=300(K), \rho=2330\left(\mathrm{~kg} \mathrm{~m}^{-3}\right), K=141.04\left(\mathrm{Wm}^{-1} \mathrm{k}^{-1}\right), C_{v}=1.64 \times 10^{6}\left(\mathrm{Jm}^{-3} \mathrm{~K}^{-1}\right), E=165(\mathrm{GPa}) \\
& \alpha_{T}=2.6 \times 10^{-6}\left(\mathrm{~K}^{-1}\right), \tau_{T}=5.0 \times 10^{-7}(\mathrm{~s}), \tau_{q}=5.0 \times 10^{-6}(\mathrm{~s}), \tau_{0}=5.0 \times 10^{-10}(\mathrm{~s})
\end{aligned}
$$

The aspect ratios of the beam are assumed $L=50 \times h$ and $b=4 \times h$. For the microscale beam, we will take the beam's thickness $h=1.0 \times 10^{-7}(\mathrm{~m})$.

Figures 2 and 3 represent the thermal quality factor $\left(\frac{1}{Q}\right)$ in the context of LordShulman and Tzou models based on the classical case when $\beta=1.0$, classical Caputo (C-C), and Caputo-Fabrizio (F-C) fractional derivative definitions, respectively. We considered two different values of the fractional-order parameter $\beta=(0.8,0.3)$ when $L=50 h, b=4 h$, $q=4.73 / L$, and $F=10^{-40}$ to stand on its effect on the thermal quality factor.

Figure 2 shows that the type of the fractional derivative and the values of the fractionalorder parameter $\beta$ have significant effects on the thermal quality factor in the context of the Lord-Shulman and Tzou models. The thermal quality factor values are close in the context of Caputo-Fabrizio based on Lord-Shulman and Tzou models. The peak points are in the following order:

$$
\begin{aligned}
& Q_{\text {Max }}^{-1}(\operatorname{Tozu}(\mathrm{C}-\mathrm{F}))>Q_{\text {Max }}^{-1}(\mathrm{~L}-\mathrm{S}(\mathrm{C}-\mathrm{F}))> \\
& Q_{\text {Max }}^{-1}(\mathrm{~L}-\mathrm{S})>Q_{\text {Max }}^{-1}(\operatorname{Tozu}(\mathrm{C}-\mathrm{C}))>Q_{\text {Max }}^{-1}(\mathrm{~L}-\mathrm{S}(\mathrm{C}-\mathrm{C}))>Q_{\text {Max }}^{-1}(\text { Tozu })
\end{aligned}
$$

Figure 3 shows that when $\beta=1.0$ and $\beta=0.3$, the values of the thermal quality factor are not close in the context of Caputo-Fabrizio based on the Lord-Shulman and Tzou models, as in Figure 1. Moreover, a change in the fractional-order parameter value leads to a change in the values of the six models' peak points. The peak points are in the following order: 


$$
\begin{aligned}
& Q_{\text {Max }}^{-1}(\operatorname{Tozu}(\mathrm{C}-\mathrm{F}))>Q_{\text {Max }}^{-1}(\mathrm{~L}-\mathrm{S}(\mathrm{C}-\mathrm{F}))>Q_{\text {Max }}^{-1}(\operatorname{Tozu}(\mathrm{C}-\mathrm{C}))> \\
& Q_{\text {Max }}^{-1}(\mathrm{~L}-\mathrm{S})>Q_{\text {Max }}^{-1}(\operatorname{Tozu})>Q_{\text {Max }}^{-1}(\mathrm{~L}-\mathrm{S}(\mathrm{C}-\mathrm{C}))
\end{aligned}
$$

Figures 4 and 5 represent the thermal quality factor $\left(\frac{1}{Q}\right)$ in the context of LordShulman and Tzou models based on the classical Caputo (C-C) and Caputo-Fabrizio (F-C) factional derivative definitions, respectively. We considered two different values of the fractional-order parameter $\beta=(0.3,0.8)$ when $L=50 h, b=4 h, q=4.73 / L$, and $F=10^{-40}$ to stand on its effect on the thermal quality factor.

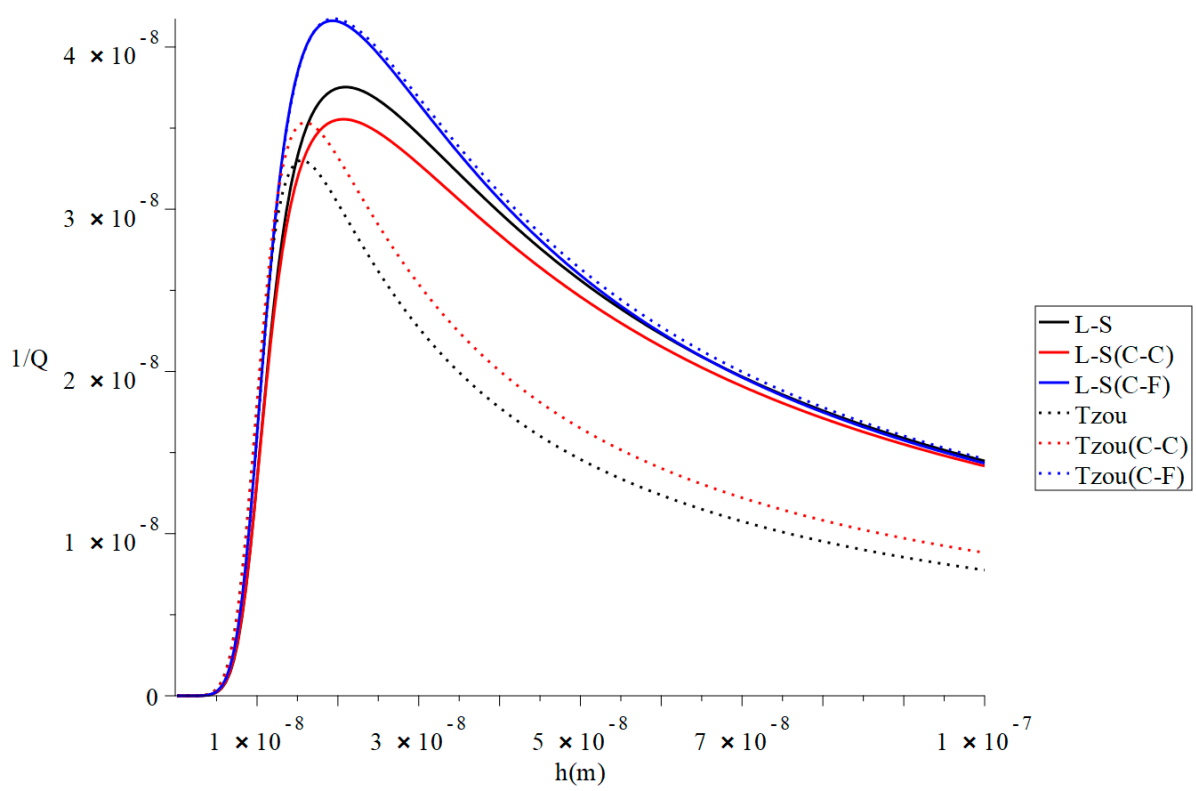

Figure 2. The thermal quality factor is based on the Lord-Shulman (L-S) and Tzou models with various fractional derivative types $\beta=0.8, L=50 h, b=4 h, q=4.73 / L$, and $F=10^{-40}$.

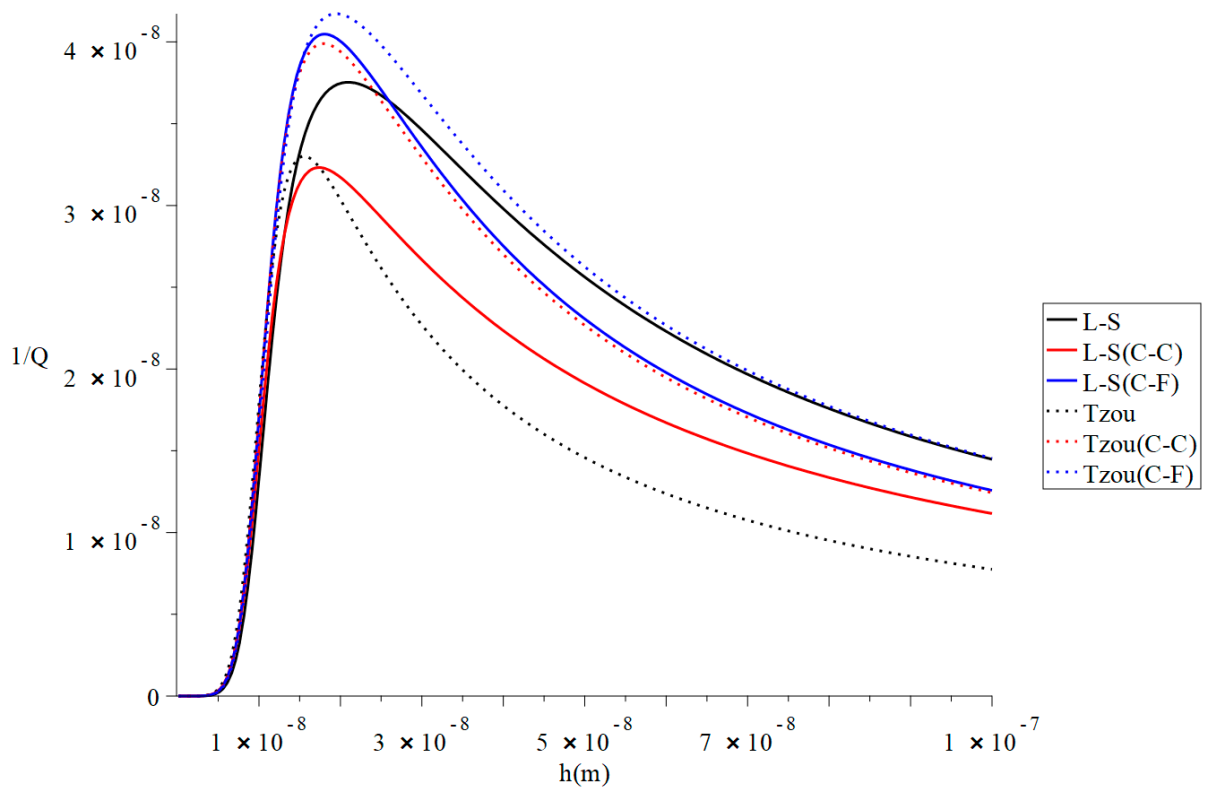

Figure 3. The thermal quality factor is based on the Lord-Shulman (L-S) and Tzou models with various fractional derivative types $\beta=0.3, L=50 h, b=4 h, q=4.73 / L$, and $F=10^{-40}$. 


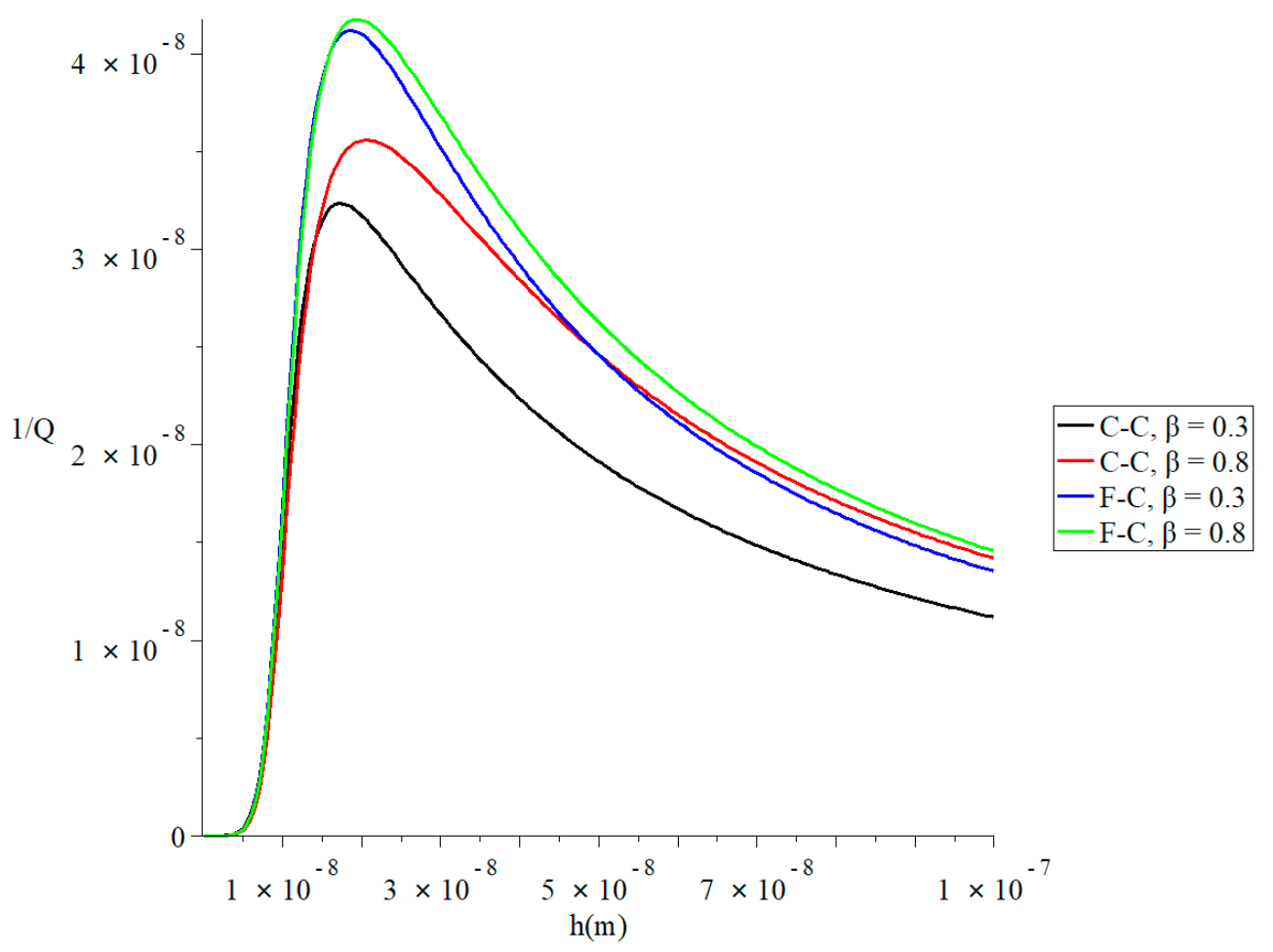

Figure 4. The thermal quality factor is based on the Lord-Shulman model with various fractional derivative types when $L=50 h, b=4 h, q=4.73 / L$, and $F=10^{-40}$.

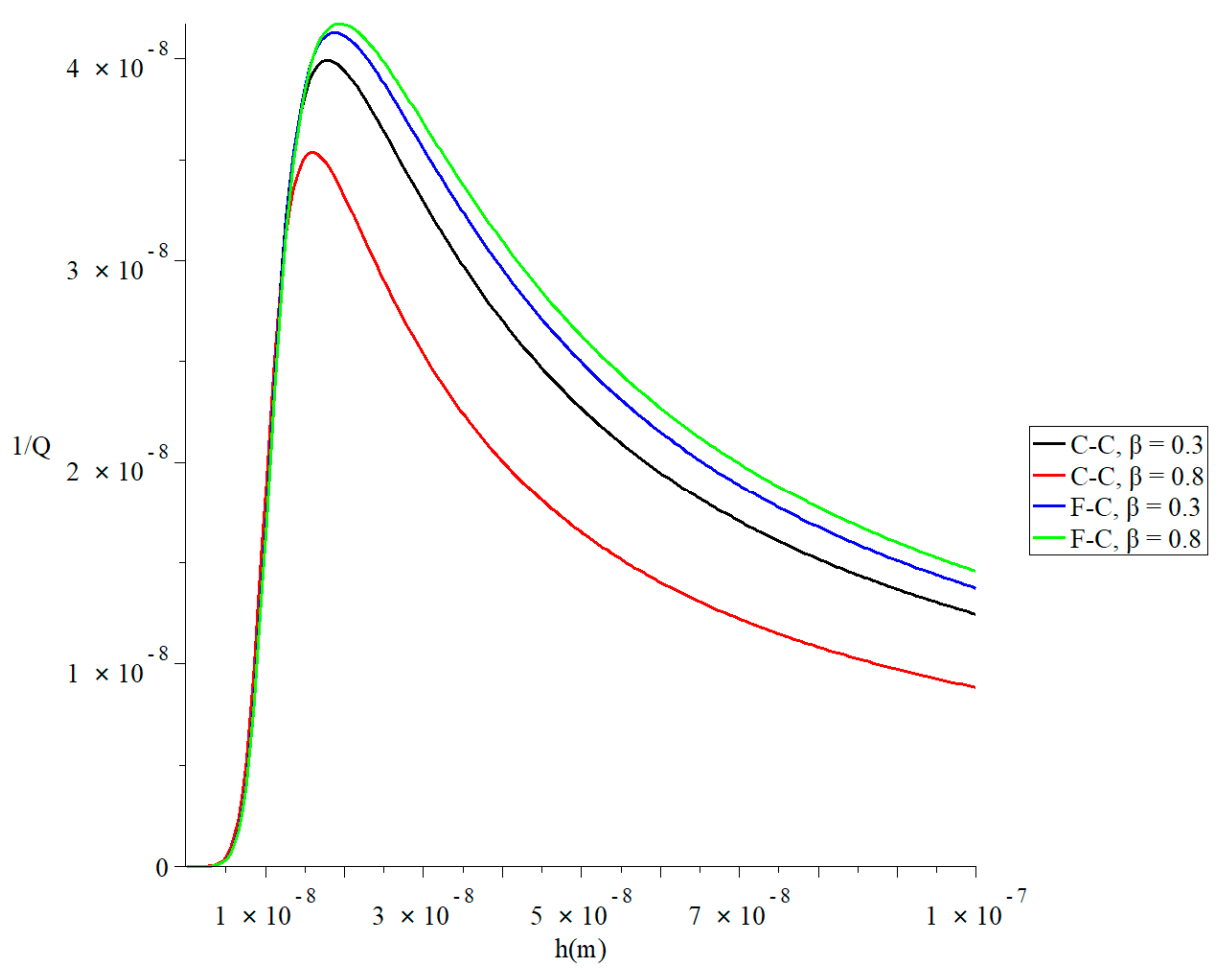

Figure 5. The thermal quality factor is based on the Tzou model with various fractional derivative types when $L=50 h, b=4 h, q=4.73 / L$, and $F=10^{-40}$.

Figure 4 shows that the type of the fractional derivative and the fractional-order parameter values $\beta$ have significant effects on the thermal quality factor in the context of the Lord-Shulman model. In the context of the two studied types of fractional derivative 
definition, an increase in the value $\beta$ leads to an increase in the thermal quality factor's value. Each curve has a peak point, which is in the following order:

$$
Q_{\text {Max }}^{-1}(F-C, \beta=0.8)>Q_{\text {Max }}^{-1}(F-C, \beta=0.3)>Q_{\text {Max }}^{-1}(C-C, \beta=0.8)>Q_{\text {Max }}^{-1}(C-C, \beta=0.3)
$$

Figure 5 shows that the type of the fractional derivative and the fractional-order parameter values $\beta$ have significant effects on the thermal quality factor in the context of the Tzou model. In the context of the classical Caputo fractional derivative definition, an increase in the value $\beta$ leads to an increase in the thermal quality factor's value. In the Caputo-Fabrizio model, an increase in the value $\beta$ leads to a decrease in the thermal quality factor's value. Each curve has a peak point, which is in the following order:

$$
Q_{\text {Max }}^{-1}(\mathrm{~F}-\mathrm{C}, \beta=0.8)>Q_{\text {Max }}^{-1}(\mathrm{~F}-\mathrm{C}, \beta=0.3)>Q_{\text {Max }}^{-1}(\mathrm{C}-\mathrm{C}, \beta=0.3)>Q_{\text {Max }}^{-1}(\mathrm{C}-\mathrm{C}, \beta=0.8)
$$

Figure 6 represents the thermal quality factor for different models with various values of the force due to static prestress $F=\left(0.0,10^{-40}\right) \mathrm{N}$ when $L=50 h, b=4 h, q=4.73 / L$ and $\beta=0.6$ to stand on its effect on the thermal quality factor. This figure shows that the force's value due to static prestress significantly impacts the thermal quality factor under the two studied models of heat conduction and the two studied definitions of a fractional derivative. Moreover, the force's effects due to static prestress in the context of the Lord-Shulman model are not the same in the context of the Tzou model. To clarify that, we focus on the values of the peak points of the thermal quality factor, which take the following orders:

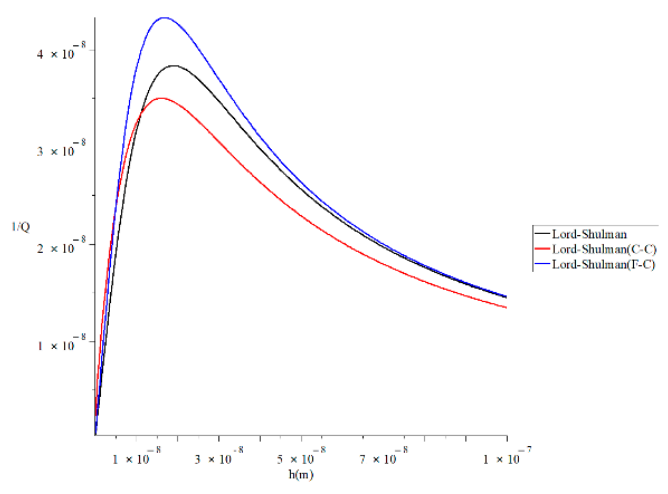

(a)

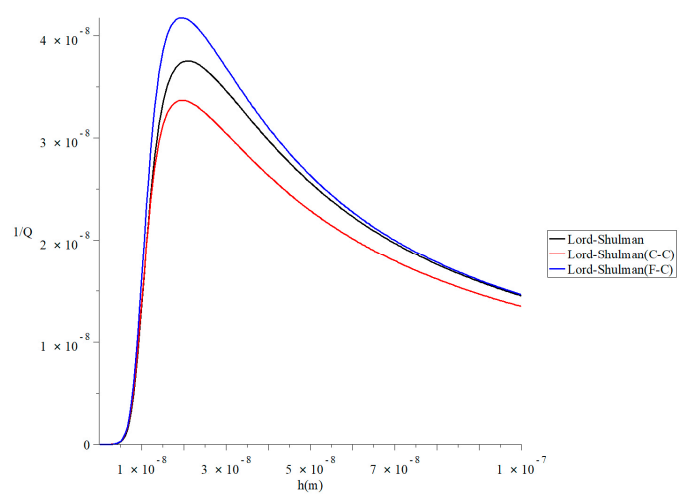

(c)

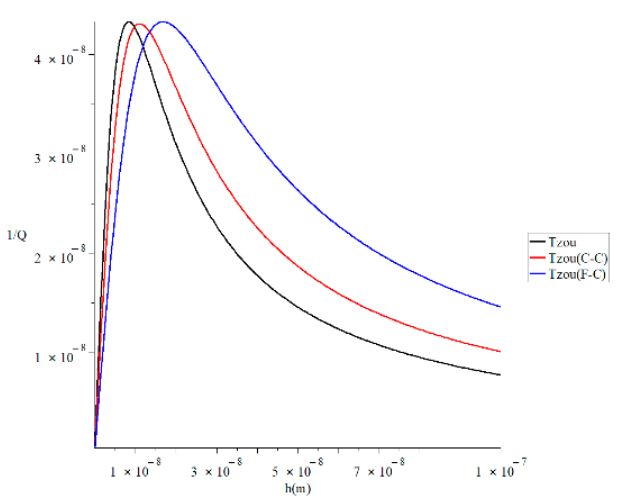

(b)

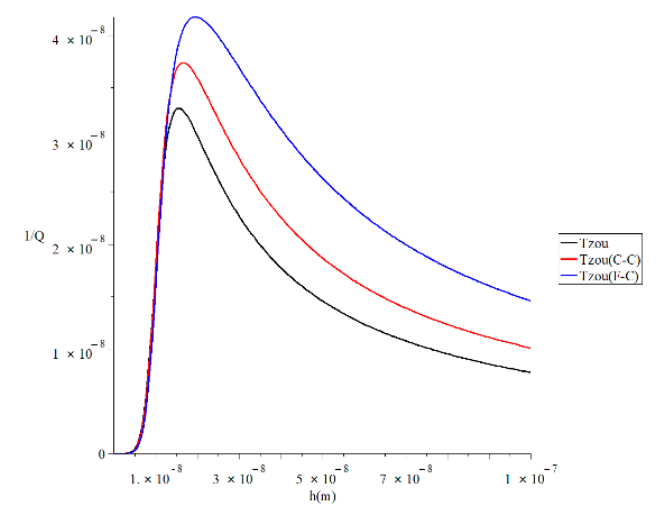

(d)

Figure 6. The thermal quality factor for different models with various values of the force due to static prestress when $L=50 h, b=4 h, q=4.73 / L$, and $\beta=0.6$. (a) The thermal quality factor for the Lord-Shulman model when $F=0.0 N$; (b) the thermal quality factor for the Tzou model when $F=0.0 \mathrm{~N}$; (c) the thermal quality factor for the Lord-Shulman model when $F=10^{-40} \mathrm{~N}$; (d) the thermal quality factor for the Tzou model when $F=10^{-40} \mathrm{~N}$.

In Figure 6a, the maximum values of the quality factor take the following order:

$$
Q_{\text {Max }}^{-1}(L-S(F-C), F=0.0)>Q_{\text {Max }}^{-1}(L-S, F=0.0)>Q_{\text {Max }}^{-1}(L-S(C-C), F=0.0)
$$


In Figure $6 \mathrm{~b}$, the maximum values of the quality factor take the following order:

$$
Q_{\text {Max }}^{-1}(\operatorname{Tzou}(F-C), F=0.0) \approx Q_{\text {Max }}^{-1}(T z o u, F=0.0) \approx Q_{\text {Max }}^{-1}(\operatorname{Tzou}(C-C), F=0.0)
$$

In Figure $6 c$, the maximum values of the quality factor take the following order:

$$
Q_{\text {Max }}^{-1}\left(L-S(F-C), F=10^{-40}\right)>Q_{\text {Max }}^{-1}\left(L-S, F=10^{-40}\right)>Q_{\text {Max }}^{-1}\left(L-S(C-C), F=10^{-40}\right)
$$

In Figure 6d, the maximum values of the quality factor take the following order:

$$
Q_{\text {Max }}^{-1}\left(L-S(F-C), F=10^{-40}\right)>Q_{\text {Max }}^{-1}\left(L-S(C-C), F=10^{-40}\right)>Q_{\text {Max }}^{-1}\left(L-S, F=10^{-40}\right)
$$

Figure 7 represents the thermal quality factor for different models with various isothermal values of natural frequency $\omega_{0}(q)=\omega_{0}(4.73 / L, 7.85 / L)$ when $L=50 h, b=4 h$, $F=10^{-40} \mathrm{~N}$ and $\beta=0.6$ to stand on its effect on the thermal quality factor. This figure shows that the isothermal value of natural frequency significantly impacts the thermal quality factor under the two studied heat conduction models and the two studied definitions of a fractional derivative. Moreover, the effects of the isothermal values of natural frequency in the Lord-Shulman model are not the same in the context of the Tzou model. To clarify that, we focus on the values of the peak points of the thermal quality factor, which take the following orders:

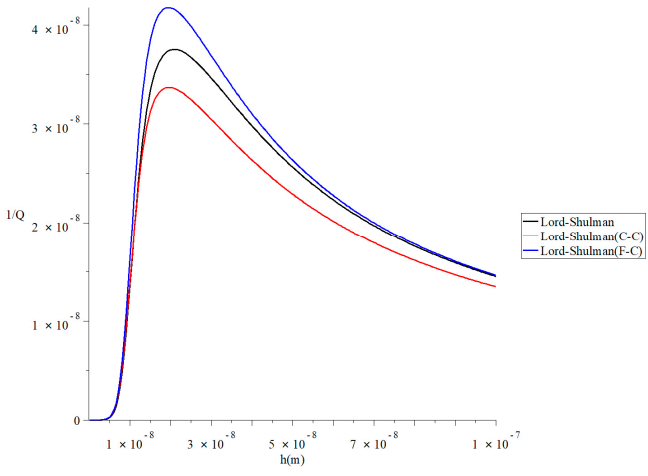

(a)

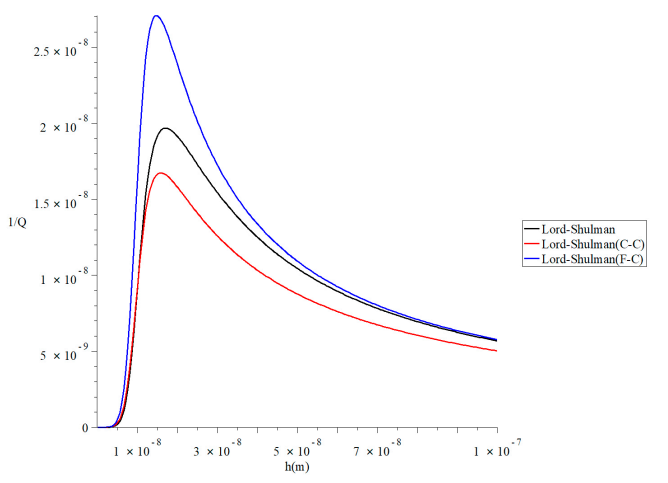

(c)

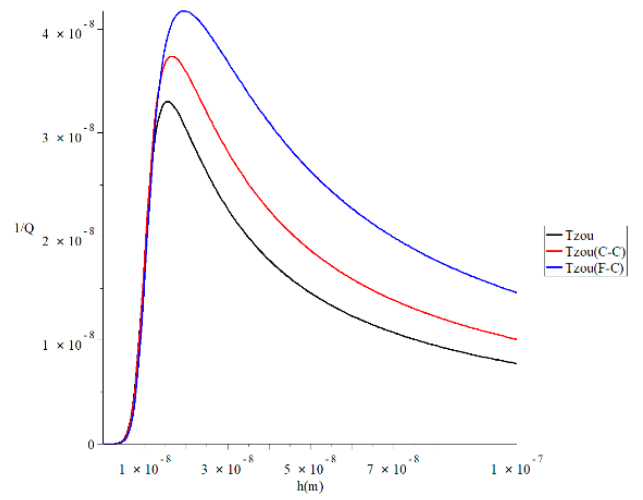

(b)

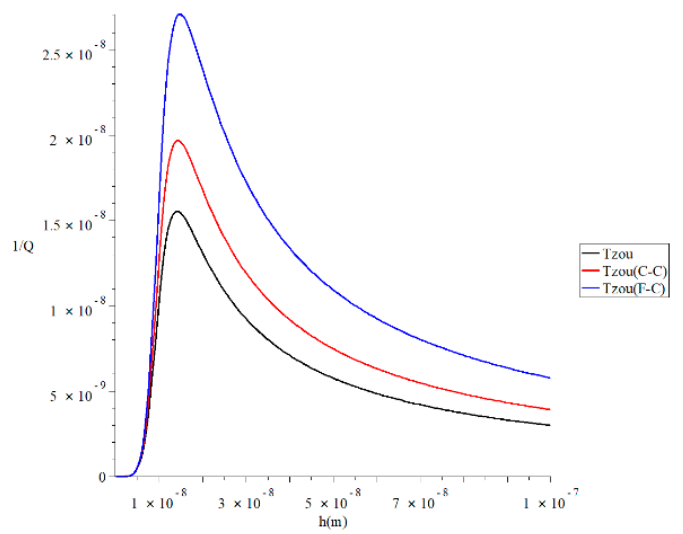

(d)

Figure 7. The thermal quality factor for different models with various isothermal values of natural frequency when $L=50 h, b=4 h, F=10^{-40} N$, and $\beta=0.6$. (a) The thermal quality factor for the Lord-Shulman model when $q=4.73 / L$; (b) the thermal quality factor for the Tzou model when $q=4.73 / L$; (c) the thermal quality factor for the Lord-Shulman model when $q=7.85 / L ;(d)$ the thermal quality factor for the Tzou model when $q=7.85 / L$.

In Figure 7a, the maximum values of the quality factor take the following order:

$$
Q_{\text {Max }}^{-1}(L-S(F-C), q=4.73 / L)>Q_{M a x}^{-1}(L-S, q=4.73 / L)>Q_{M a x}^{-1}(L-S(C-C), q=4.73 / L)
$$


In Figure $7 \mathrm{~b}$, the maximum values of the quality factor take the following order:

$$
Q_{\text {Max }}^{-1}(\operatorname{Tzou}(F-C), q=4.73 / L)>Q_{\text {Max }}^{-1}(\operatorname{Tzou}(C-C), q=4.73 / L)>Q_{\text {Max }}^{-1}(T z o u, q=4.73 / L)
$$

In Figure $7 \mathrm{c}$, the maximum values of the quality factor take the following order:

$$
Q_{\text {Max }}^{-1}(L-S(F-C), q=7.83 / L)>Q_{\text {Max }}^{-1}(L-S, q=7.83 / L)>Q_{\text {Max }}^{-1}(L-S(C-C), q=7.83 / L)
$$

In Figure $7 \mathrm{~d}$, the maximum values of the quality factor take the following order:

$$
Q_{\text {Max }}^{-1}(\operatorname{Tzou}(F-C), q=7.85 / L)>Q_{\text {Max }}^{-1}(\operatorname{Tzou}(C-C), q=7.85 / L)>Q_{\text {Max }}^{-1}(T z o u, q=7.85 / L)
$$

Figure 8 represents the thermal quality factor for different models with various values of the beam's length $L=(30,50) h$ when $q=4.73 / L b=4 h, F=10^{-40} N$, and $\beta=0.6$ to stand on its effect on the thermal quality factor. This figure shows that the value of the beam's size significantly impacts the thermal quality factor under the two studied models of heat conduction and the two studied definitions of a fractional derivative. Moreover, the effects of the beam's length in the Lord-Shulman model's context are not the same in the context of the Tzou model. To clarify that, we focus on the values of the peak points of the thermal quality factor, which take the following orders.

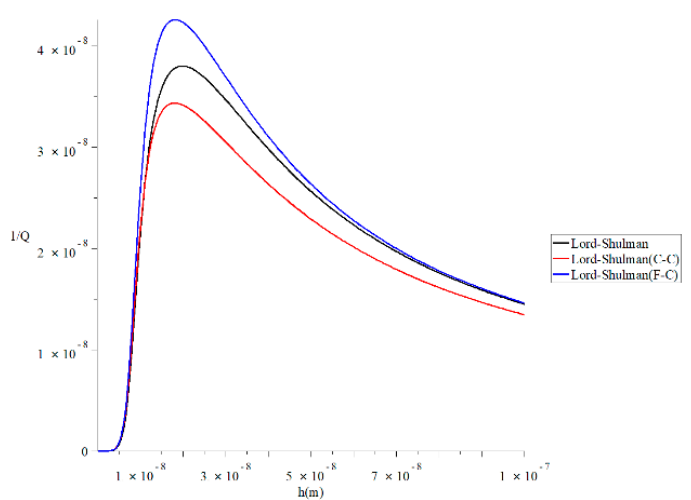

(a)

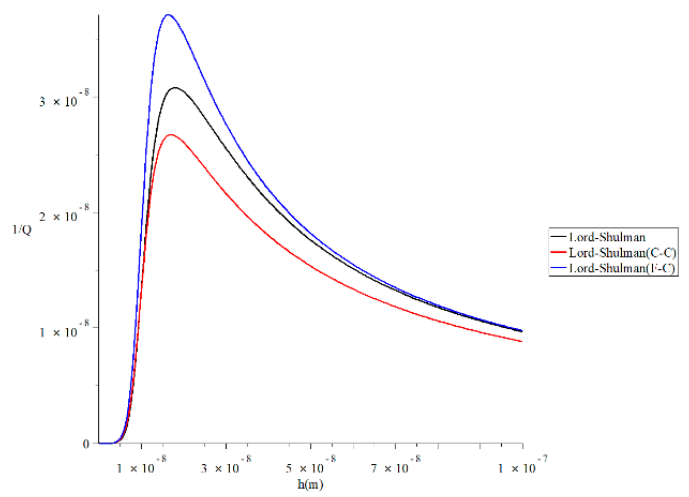

(c)

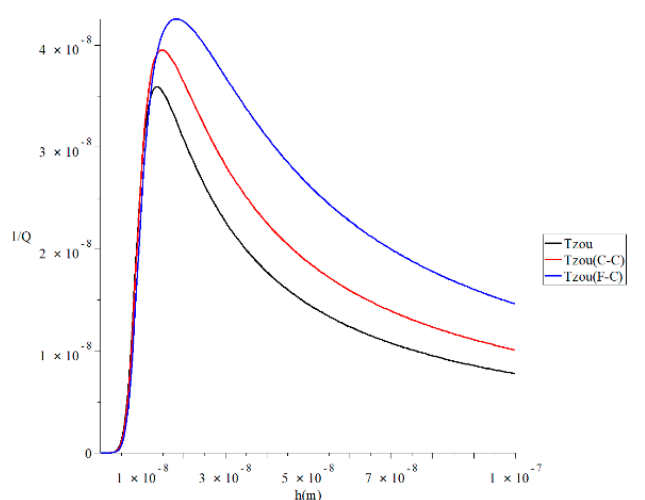

(b)

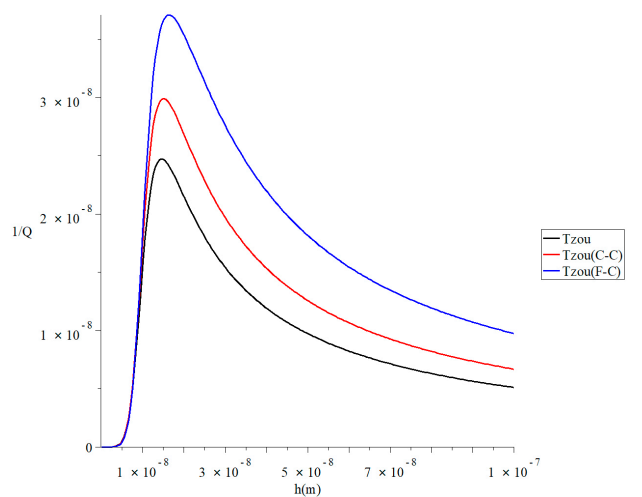

(d)

Figure 8. The thermal quality factor for different models with various values of the beam's length when $q=4.73 / L, b=4 h, F=10^{-40} N$, and $\beta=0.6$. (a) The thermal quality factor for the Lord-Shulman model when $L=30 \mathrm{~h}$; (b) the thermal quality factor for the Tzou model when $L=30 \mathrm{~h}$; (c) the thermal quality factor for the Lord-Shulman model when $L=50 \mathrm{~h}$; (d) the thermal quality factor for the Tzou model when $L=50 \mathrm{~h}$.

In Figure 8a, the maximum values of the quality factor take the following order:

$$
Q_{\text {Max }}^{-1}(L-S(F-C), L=30 h)>Q_{\text {Max }}^{-1}(L-S, L=30 h)>Q_{\text {Max }}^{-1}(L-S(C-C), L=30 h)
$$

In Figure $8 \mathrm{~b}$, the maximum values of the quality factor take the following order:

$$
Q_{\text {Max }}^{-1}(\operatorname{Tzou}(F-C), L=30 h)>Q_{\text {Max }}^{-1}(\operatorname{Tzou}(C-C), L=30 h)>Q_{\text {Max }}^{-1}(\text { Tzou, } L=30 h)
$$


In Figure $8 \mathrm{c}$, the maximum values of the quality factor take the following order:

$Q_{\text {Max }}^{-1}(L-S(F-C), L=50 h)>Q_{\text {Max }}^{-1}(L-S, L=50 h)>Q_{\text {Max }}^{-1}(L-S(C-C), L=50 h)$

In Figure $8 \mathrm{~d}$, the maximum values of the quality factor take the following order:

$Q_{\text {Max }}^{-1}(\operatorname{Tzou}(F-C), L=50 h)>Q_{\text {Max }}^{-1}(\operatorname{Tzou}(C-C), L=50 h)>Q_{\text {Max }}^{-1}(T z o u, L=50 h)$

To verify the results, we take the value of the fractional-order parameter $\beta=1$, then the results in the current work are the same as $[8,19,20,42,43,49,57,58]$.

\section{Conclusions}

A thermal study of the thermal quality factor was applied. A force attributable to static prestress was found to create a purely assisted microbeam resonator made of silicon (Si). The governing equations have been built in the context of the six different thermal conductivity models, the traditional Lord-Shulman, the classical Lord-Shulman based on Caputo, Lord-Shulman based on the Fabrizio-Caputo, the traditional Tzou, the classical Caputo, and the fractional Fabrizio-Caputo.

The findings demonstrate that the thermal quality factor's intensity has significant consequences attributable to static prestress, fractional order parameters, natural frequency isothermal strength, and beam length.

The two fractional derivatives definitions influence the thermal quality factor differently and substantially.

The thermal quality factor obtains a maximum value in the context of the Tzou dualphase lag model or Lord-Shulman model when it is based on the fractional Fabrizio-Caputo definition.

An increase in the fractional-order parameter leads to an increase in the thermal quality value of the nanobeam.

Author Contributions: H.M.Y. Suggested the model, constructed the equation, wrote the paper draft. A.A.E.-B., solved the model, figured the results, revised the paper. E.A.N.A.-L., wrote discussion, wrote conclusion, wrote the final draft, revised the paper. All authors have read and agreed to the published version of the manuscript.

Funding: This research received no external funding.

Conflicts of Interest: The authors declare no conflict of interest.

\section{References}

1. Duwel, A.; Candler, R.N.; Kenny, T.W.; Varghese, M. Engineering MEMS resonators with low thermoelastic damping. J. Microelectromech. Syst. 2006, 15, 1437-1445. [CrossRef]

2. Guo, F.; Rogerson, G. Thermoelastic coupling effect on a micro-machined beam resonator. Mech. Res. Commun. 2003, 30, 513-518. [CrossRef]

3. Harris, C.M.; Piersol, A.G. Harris' Shock and Vibration Handbook; McGraw-Hill: New York, NY, USA, 2002; Volume 5.

4. Koyama, T.; Bindel, D.S.; He, W.; Quévy, E.P.; Govindjee, S.; Demmel, J.W.; Howe, R.T. Simulation tools for damping in high frequency resonators. In Proceedings of the IEEE SENSORS, Irvine, CA, USA, 30 October-3 November 2005; p. 4.

5. Zener, C. Internal friction in solids. I. Theory of internal friction in reeds. Phys. Rev. 1937, 52, 230. [CrossRef]

6. Zener, C. Internal friction in solids II. General theory of thermoelastic internal friction. Phys. Rev. 1938, 53, 90. [CrossRef]

7. Zener, C.; Otis, W.; Nuckolls, R. Internal friction in solids III. Experimental demonstration of thermoelastic internal friction. Phys. Rev. 1938, 53, 100. [CrossRef]

8. Lifshitz, R.; Roukes, M.L. Thermoelastic damping in micro-and nanomechanical systems. Phys. Rev. B 2000, 61, 5600. [CrossRef]

9. Sun, Y.; Fang, D.; Soh, A.K. Thermoelastic damping in micro-beam resonators. Int. J. Solids Struct. 2006, 43, 3213-3229. [CrossRef]

10. Sharma, J.; Sharma, R. Damping in micro-scale generalized thermoelastic circular plate resonators. Ultrasonics 2011, 51, 352-358. [CrossRef]

11. Tzou, D. On the thermal shock wave induced by a moving heat source. J. Heat Transf. 1989, 111, 232-238. [CrossRef]

12. Tzou, D.; Puri, P. Macro-to microscale heat transfer: The lagging behavior. Appl. Mecha. Rev. 1997, 50, B82. [CrossRef]

13. Xu, M.; Guo, J.; Wang, L.; Cheng, L. Thermal wave interference as the origin of the overshooting phenomenon in dual-phaselagging heat conduction. Int. J. Therm. Sci. 2011, 50, 825-830. [CrossRef]

14. Al-Huniti, N.S.; Al-Nimr, M. Thermoelastic behavior of a composite slab under a rapid dual-phase-lag heating. J. Therm. Stresses 2004, 27, 607-623. [CrossRef] 
15. Ho, J.-R.; Kuo, C.-P.; Jiaung, W.-S. Study of heat transfer in multilayered structure within the framework of dual-phase-lag heat conduction model using lattice Boltzmann method. Int. J. Heat Mass Transf. 2003, 46, 55-69. [CrossRef]

16. Lee, Y.-M.; Tsai, T.-W. Ultra-fast pulse-laser heating on a two-layered semi-infinite material with interfacial contact conductance. Int. Commun. Heat Mass Transf. 2007, 34, 45-51. [CrossRef]

17. Liu, K.-C. Numerical analysis of dual-phase-lag heat transfer in a layered cylinder with nonlinear interface boundary conditions. Comput. Phys. Commun. 2007, 177, 307-314. [CrossRef]

18. Ramadan, K. Semi-analytical solutions for the dual phase lag heat conduction in multilayered media. Int. J. Therm. Sci. 2009, 48, 14-25. [CrossRef]

19. Alghamdi, N. Dual-Phase-Lagging Thermoelastic Damping Vibration in Micro-Nano Scale Beam Resonators with Voids. Int. J. Multidiscip. Curr. Res. 2017, 5, 71-78.

20. Alghamdi, N.A.; Youssef, H.M. Dual-phase-lagging thermoelastic damping in-extensional vibration of rotating nano-ring. Microsyst. Technol. 2017, 23, 4333-4343. [CrossRef]

21. Guo, F.; Song, J.; Wang, G.; Zhou, Y. Analysis of thermoelastic dissipation in circular micro-plate resonators using the generalized thermoelasticity theory of dual-phase-lagging model. J. Sound Vib. 2014, 333, 2465-2474. [CrossRef]

22. Guo, F.; Wang, G.; Rogerson, G. Analysis of thermoelastic damping in micro-and nanomechanical resonators based on dualphase-lagging generalized thermoelasticity theory. Int. J. Eng. Sci. 2012, 60, 59-65. [CrossRef]

23. Dai, H.; Zheng, Z.; Wang, W. A new fractional wavelet transform. Commun. Nonlinear Sci. Numer. Simul. 2017, 44, 19-36. [CrossRef]

24. Zheng, Z.; Dai, H. A new fractional equivalent linearization method for nonlinear stochastic dynamic analysis. Nonlinear Dyn. 2018, 91, 1075-1084. [CrossRef]

25. Dai, H.; Zheng, Z.; Ma, H. An explicit method for simulating non-Gaussian and non-stationary stochastic processes by KarhunenLoève and polynomial chaos expansion. Mech. Syst. Signal Process. 2019, 115, 1-13. [CrossRef]

26. Povstenko, Y. Fractional Thermoelasticity; Springer: Cham, Switzerland, 2015; Volume 219.

27. Colinas-Armijo, N.; Di Paola, M.; Di Matteo, A. Fractional viscoelastic behaviour under stochastic temperature process. Probabilistic Eng. Mech. 2018, 54, 37-43. [CrossRef]

28. $\mathrm{Xu}, \mathrm{J}$. A PDEM based new methodology for stochastic dynamic stability control of nonlinear structures with fractional-type viscoelastic dampers. J. Sound Vib. 2016, 362, 16-38. [CrossRef]

29. Xu, J.; Wang, D.; Dang, C. A marginal fractional moments based strategy for points selection in seismic response analysis of nonlinear structures with uncertain parameters. J. Sound Vib. 2017, 387, 226-238. [CrossRef]

30. Khalil, R.; Al Horani, M.; Yousef, A.; Sababheh, M. A new definition of fractional derivative. J. Comput. Appl. Math. 2014, 264, 65-70. [CrossRef]

31. Baleanu, D.; Fernandez, A. On some new properties of fractional derivatives with Mittag-Leffler kernel. Commun. Nonlinear Sci. Numer. Simul. 2018, 59, 444-462. [CrossRef]

32. Atangana, A. On the new fractional derivative and application to nonlinear Fisher's reaction-diffusion equation. Appl. Math. Comput. 2016, 273, 948-956. [CrossRef]

33. Youssef, H.M. Theory of fractional order generalized thermoelasticity. J. Heat Transf. 2010, 132, 061301-061308. [CrossRef]

34. Youssef, H.M. Theory of generalized thermoelasticity with fractional order strain. J. Vib. Control 2016, 22, 3840-3857. [CrossRef]

35. Sherief, H.H.; El-Sayed, A.; El-Latief, A.A. Fractional order theory of thermoelasticity. Int. J. Solids Struct. 2010, 47, 269-275. [CrossRef]

36. Podlubny, I. Fractional Differential Equations: An Introduction to Fractional Derivatives, Fractional Differential Equations, to Methods of Their Solution and Some of Their Applications; Elsevier: Amsterdam, The Netherlands, 1998.

37. Caputo, M.; Fabrizio, M. A new definition of fractional derivative without singular kernel. Progr. Fract. Differ. Appl 2015, 1, 1-13.

38. Shaker, F.J. Effect of axial load on mode shapes and frequencies of beams. Natl. Aeronaut. Space Adm. 1975, $21,1-32$.

39. Verbridge, S.S.; Shapiro, D.F.; Craighead, H.G.; Parpia, J.M. Macroscopic tuning of nanomechanics: Substrate bending for reversible control of frequency and quality factor of nanostring resonators. Nano Lett. 2007, 7, 1728-1735. [CrossRef] [PubMed]

40. Tzou, D.Y. Macro-to Microscale Heat Transfer: The Lagging Behavior; John Wiley \& Sons: Hoboken, NJ, USA, 2014.

41. Majchrzak, E.; Mochnacki, B. Dual-phase lag model of thermal processes in a multi-layered microdomain subjected to a strong laser pulse using the implicit scheme of FDM. Int. J. Therm. Sci. 2018, 133, 240-251. [CrossRef]

42. Zhou, H.; Li, P.; Zuo, W.; Fang, Y. Dual-phase-lag thermoelastic damping models for micro/nanobeam resonators. Appl. Math. Model. 2020, 79, 31-51. [CrossRef]

43. Kumar, H.; Mukhopadhyay, S. Analysis of the quality factor of micro-beam resonators based on heat conduction model with a single delay term. J. Therm. Stresses 2019, 42, 929-942. [CrossRef]

44. Samko, S.G.; Kilbas, A.A.; Marichev, O.I. Fractional Integrals and Derivatives; Gordon and Breach Science Publishers: Yverdon Yverdon-les-Bains, Switzerland, 1993; Volume 1.

45. Hilfer, R. Applications of Fractional Calculus in Physics; World Scientific Singapore: Singapore, 2000; Volume 35.

46. Saad, K.M. New fractional derivative with non-singular kernel for deriving Legendre spectral collocation method. Alex. Eng. J. 2019, 59, 1909-1917. [CrossRef]

47. Sherief, H.H.; Hussein, E.M. The effect of fractional thermoelasticity on two-dimensional problems in spherical regions under axisymmetric distributions. J. Therm. Stresses 2020, 43, 440-455. [CrossRef] 
48. Grover, D.; Seth, R. Viscothermoelastic micro-scale beam resonators based on dual-phase lagging model. Microsyst. Technol. 2018, 24, 1667-1672. [CrossRef]

49. Sun, Y.; Saka, M. Thermoelastic damping in micro-scale circular plate resonators. J. Sound Vib. 2010, 329, 328-337. [CrossRef]

50. Tzou, D. Experimental support for the lagging behavior in heat propagation. J. Thermophys. Heat. Trans. 1995, 9, 686-693.

51. Youssef, H. Theory of two-temperature-generalized thermoelasticity. Ima J. Appl. Math. 2006, 71, 383-390.

52. Garrappa, R.; Kaslik, E.; Popolizio, M. Evaluation of fractional integrals and derivatives of elementary functions: Overview and tutorial. Mathematics 2019, 7, 407.

53. Gross, D.; Seelig, T. Fracture Mechanics: With an Introduction to Micromechanics; Springer: Cham, Switzerland, 2017.

54. Lord, H.W.; Shulman, Y. A generalized dynamical theory of thermoelasticity. J. Mech. Phys. Solids 1967, 15, 299-309. [CrossRef]

55. Li, P.; Fang, Y.; Hu, R. Thermoelastic damping in rectangular and circular microplate resonators. J. Sound Vib. 2012, 331, 721-733. [CrossRef]

56. Rahimi, Z.; Sumelka, W.; Ahmadi, S.R.; Baleanu, D. Study and control of thermoelastic damping of in-plane vibration of the functionally graded nano-plate. J. Vib. Control 2019, 25, 2850-2862. [CrossRef]

57. Hoang, C.M. Thermoelastic damping depending on vibration modes of nano beam resonator. Commun. Phys. 2015, 25, 317. [CrossRef]

58. Youssef, H.M.; Alghamdi, N. Thermoelastic damping in nanomechanical resonators based on two-temperature generalized thermoelasticity theory. J. Therm. Stresses 2015, 38, 1345-1359. 